\title{
Anti-inflammatory effects of LASSBio-998, a new drug candidate designed to be a p38 MAPK inhibitor, in an experimental model of acute lung inflammation
}

\author{
Aline C. Brando Lima1, Alexandre L. Machado, Patrícia Simon ${ }^{1}$, Moisés \\ M. Cavalcante ${ }^{1}$, Daniele C. Rezende ${ }^{2}$, Gilberto M. Sperandio da Silva ${ }^{3}$, \\ Paulo Gustavo B. D. Nascimento ${ }^{4}$, Luis E. M. Quintas ${ }^{2}$, Fernando Q. \\ Cunha ${ }^{4}$, Eliezer J. Barreiro ${ }^{3}$, Lídia M. Lima ${ }^{3}$, Vera L.G. Koatz ${ }^{1, \dagger}$ \\ ${ }^{1}$ Laboratory of Cellular Immunopharmacology, Institute of Medical Biochemistry, Federal University \\ of Rio de Janeiro, CCS, 21941-902, Rio de Janeiro, Brazil \\ ${ }^{2}$ Laboratory of Biochemical and Molecular Pharmacology, Institute of Biomedical Sciences, Federal University \\ of Rio de Janeiro, CCS, 21941-902, Rio de Janeiro, Brazil \\ ${ }^{3}$ Laboratory of Evaluation and Synthesis of Bioactive Substances (LASSBio), Faculty of Pharmacy, Federal \\ University of Rio de Janeiro, CCS, 21944-971, Rio de Janeiro, Brazil \\ ${ }^{4}$ Laboratory of Pain and Inflammation, Department of Pharmacology, Faculty of Medicine of Ribeirão Preto, \\ University of São Paulo, São Paulo, Brazil
}

Correspondence: L.E.M. Quintas, e-mail: Iquintas@farmaco.ufrj.br; L.M. Lima, e-mail: lidia@pharma.ufrj.br

\begin{abstract}
:
We investigated the effects of LASSBio-998 (L-998), a compound designed to be a p38 MAPK (mitogen-activated protein kinase) inhibitor, on lipopolysaccharide (LPS)-induced acute lung inflammation in vivo. BALB/c mice were challenged with aerosolized LPS inhalation $(0.5 \mathrm{mg} / \mathrm{ml}) 4 \mathrm{~h}$ after oral administration of L-998. Three hours after LPS inhalation, bronchoalveolar lavage fluid was obtained to measure the levels of the proinflammatory cytokines TNF- $\alpha$ (tumor necrosis factor- $\alpha$ ) and IL-1 (interleukin-1) and the chemokines MCP-1 (monocyte chemoattractant protein-1) and KC (keratinocyte chemoattractant). In addition, neutrophil infiltration and p38 MAPK phosphorylation was measured. L-998 inhibited LPS-induced production of TNF- $\alpha$ and IL-1 $\beta$, and did not alter KC and MCP-1 levels. Furthermore, L-998 also significantly decreased neutrophil accumulation in lung tissues. As expected, L-998 diminished p38 MAPK phosphorylation and reduced acute lung inflammation. Inhibition of p38 MAPK phosphorylation by L-998 was also demonstrated in LPS-challenged murine C57BL/6 peritoneal macrophages in vitro, with concentration-dependent effects. L-998 suppressed LPS-induced lung inflammation, most likely by inhibition of the cytokine-p38 MAPK pathway, and we postulate that L-998 could be a clinically relevant anti-inflammatory drug candidate.
\end{abstract}

Key words:

LASSBio-998, TNF- $\alpha$, lung inflammation, p38 mitogen-activated protein kinase, anti-inflammatory drug candidate

\footnotetext{
${ }^{\dagger}$ In memoriam
} 


\begin{abstract}
Abbreviations: ALI - acute lung injury, ARDS - acute respiratory distress syndrome, BALF - bronchoalveolar lavage fluid, COX - cyclooxygenase, ICAM-1 - intercellular adhesion molecule-1, IL - interleukin, KC - keratinocyte chemoattractant, LPS - lipopolysaccharide, MAPK - mitogen-activated protein kinase, MCP-1 - monocyte chemoattractant protein-1, MIP-2 - macrophage inflammatory protein-2, MTT - (3-(4,5dimethylthiazol-2-yl)-2,5-diphenyltetrazolium bromide, NF- $\mathrm{BB}$ - nuclear factor-кB; TNF- $\alpha$ - tumor necrosis factor $\alpha$.
\end{abstract}

\section{Introduction}

Acute respiratory distress syndrome (ARDS) is characterized by acute lung inflammation with local recruitment and activation of polymorphonuclear neutrophils and release of proinflammatory mediators [5]. ARDS can lead to sepsis, trauma and severe pneumonia; sepsis, and in particular pneumonia, can cause acute lung injury (ALI). ARDS is associated with the development of interconnected inflammatory cascades, with proinflammatory cytokines playing a central role in the initiation and propagation of the inflammatory response leading to lung injury. In this respect, tumor necrosis factor- $\alpha$ (TNF- $\alpha$ ) and interleukin- $1 \beta$ (IL-1 $\beta$ ) are considered the pivotal mediators of lung inflammation in ARDS [5].

The pulmonary inflammation model utilizing acute aerosolized exposure to lipopolysaccharide (LPS) is of significant clinical interest. In the single-exposure murine model of LPS-induced pulmonary inflammation, the maximal release of cytokines occurs within $4 \mathrm{~h}$ in the airspaces. Aerosolized or intranasal administration of LPS induces intense lung inflammation, with macrophage activation and neutrophil recruitment to the interstitium, alveoli and airways of guinea-pigs [18], rats [44] and mice [17]. LPS is not an effective chemoattractant for neutrophils, but it can trigger a trophic inflammatory cascade via synthesis of cytokines and other proinflammatory mediators by resident alveolar macrophages, local mast cells, fibroblasts, epithelia and endothelial cells $[8,16]$. The release of TNF- $\alpha$ and neutrophil-directed chemokines, such as IL-8, is essential to early LPS-mediated neutrophil recruitment $[36,43]$.

Infiltrating leukocytes are hallmarks of pulmonary inflammation associated with ALI. The expression of keratinocyte chemoattractant (KC), macrophage inflammatory protein-2 (MIP-2) or monocyte chemoattractant protein-1 (MCP-1) in airway epithelial cells is sufficient to elicit pulmonary inflammation. Earlyresponse cytokines, i.e., TNF- $\alpha$ and IL-1, can also amplify this response by stimulating the nuclear factor- $\kappa \mathrm{B}(\mathrm{NF}-\kappa \mathrm{B})$-dependent induction of proinflammatory mediators in cells [5]. More importantly, in the setting of inflammation, the release of those cytokines and other functional responses by pulmonary host defense cells are regulated by p38 mitogen-activated protein kinase (MAPK) and may be hampered by $\mathrm{p} 38$ MAPK inhibitors [37]. Different studies have shown that inhibition of p38 MAPK blocks TNF- $\alpha$ and IL-8 release by LPS-stimulated monocytes/macrophages, IL-8 release by bronchial epithelial cells, and upregulation of the intercellular adhesion molecule-1 (ICAM-1) in endothelial cells when exposed to inflammatory stimuli $[21,24,31]$. Neutrophil responses to such cytokines and other mediators is also regulated by $\mathrm{p} 38$ MAPK, which also affects cell adhesion, NF- $\kappa B$ activation, TNF- $\alpha /$ IL-8 synthesis, superoxide release, chemotaxis and apoptosis $[11,37]$.

Despite the recent development of various pharmacological therapies for the management of multiple inflammatory disorders, including ALI, ARDS and rheumatoid arthritis, none have been approved for clinical use $[13,28]$. Nevertheless, treatment with p38 MAPK inhibitors has been proposed as a selective intervention to reduce LPS-induced lung inflammation due to the ability of these inhibitors to decrease neutrophil recruitment to the airspaces [26]. These inhibitors are being studied in initial clinical trials for chronic obstructive pulmonary disease and rheumatoid arthritis $[2,28]$, and they are emerging as a new class of potential therapies for inflammatory conditions caused by excessive cytokine production.

In the present work, we report the anti-inflammatory effects of LASSBio-998 (L-998), a novel drug candidate designed to be a p38 MAPK inhibitor (Fig. 1), on LPS-induced acute lung inflammation.

\section{Materials and Methods}

\section{Animals and reagents}

Male BALB/c or C57BL/6 (for peritoneal macrophages assays) mice, weighing 20-25 g, were used for experimentation. Animal holding rooms were kept at $21-24^{\circ} \mathrm{C}$ and $40-60 \%$ relative humidity with a $12 \mathrm{~h}$ 


\section{A}<smiles>CCOC(=O)c1c(NC(=O)Nc2ccccc2)sc2c1CCC2C(C)(C)C</smiles>
CLASSICAL BIOISOSTERISM

(1)

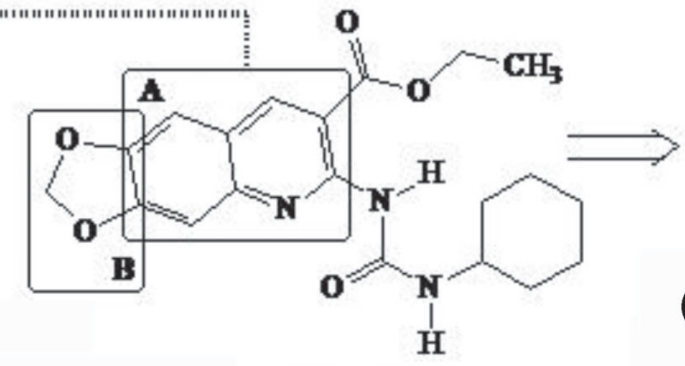

(2, LASSBio-998)<smiles>C=CCc1ccc2c(c1)OC13CCC(CC2)OC1(CC)O3</smiles>

safrole

(Piper hispidinarvium) starting material

B<smiles>CCOC(=O)c1[c-]c2cc3c(cc2nc1NC(=O)NC1[C]CCCC1)OCO3</smiles>

Fig. 1. (A) Bioisosteric strategy chart for the synthesis of LASSBio-998 (2) using the lead compound GK00687 (1) and safrole. (B) LASSBio-998 chemical structure

light/dark cycle. Mice were cared for and handled in accordance with the International Guide for the Care and Use of Laboratory Animals, and protocols were approved by the University Animal Care and Use Committee.

Antibodies were purchased from Cell Signaling (USA; anti-phosphorylated and anti-total p38 MAPK) and Santa Cruz Biotechnology (USA; anti-rabbit IgG). Celecoxib was obtained from Pfizer Pharmacia (USA), thalidomide was obtained from Sigma Chemical Co. (USA), and SB202190 was obtained from Tocris Bioscience (USA). All other analytical grade chemicals were from Sigma Chemical Co. (USA).

\section{Chemistry}

L-998 (ethyl 6-cyclohexylurea-[1,3]dioxolo[5,4-g] quinoline-7-carboxylate) was designed as a novel antiinflammatory drug candidate. It was synthesized by structural modifications on the prototype GK00687 (Fig. 1A), which was identified by high-throughput screening of the Bayer compound library [40]. These modifications were based on bioisosteric replacement [29] of the thiophene ring, which is present in the structure of the lead compound GK00687 (subunit A), by a quinoline nucleus in L-998 (subunit A) (Fig. 1A). A molecular modeling study utilizing $3 \mathrm{D}$-quantitative structure-activity relationship analysis associated with a comparative molecular field assessment was used earlier to predict p38 MAPK selectivity of L-998 [42]. The natural product safrole was used as the starting material for L-998 synthesis (Patent. WO/2006/ 128268, 2006).

\section{Synthesis of ethyl 6-cyclohexylurea-[1,3]dioxolo- [5,4-g]quinoline-7-carboxylate (LASSBio-998)}

The synthesis procedure was adapted from Dumas et al. [14]. In a reflux condenser system, a mixture of ethyl 6-amino-[1,3]dioxolo[5,4-g]quinoline-7-carboxylate (1.823 mmol; $0.5 \mathrm{~g})$, obtained as previously described [47], and cyclohexyl isocyanate $(3.65 \mathrm{mmol})$ in anhydrous toluene $(100 \mathrm{ml})$ was magnetically stirred at reflux temperature for $72 \mathrm{~h}$. The reaction medium was diluted with dichloromethane followed by rotary evaporation. Then, ethyl acetate $(100 \mathrm{ml})$ was added, and the mixture was filtered, washed with a saturated $\mathrm{NaCl}$ solution and washed again with water. The organic phase was dried with anhydrous $\mathrm{Na}_{2} \mathrm{SO}_{4}$, concentrated in rotary evaporator and purified by recrystallization from a hydroalcoholic (70\% ethanol) solution (yield: $75 \%$; m.p. $\left.{ }^{128}-130^{\circ} \mathrm{C}\right) .{ }^{1} \mathrm{H}-\mathrm{NMR}(200 \mathrm{MHz}$, DMSO-d 6 , $\delta, p p m): 1.38$ (t, 3H, $J=7 \mathrm{~Hz}, \mathrm{OCH}_{2} \underline{\mathrm{CH}}_{3}$ ); 1.04-1.88 (m, 10H, Hb e Hb', Hc e Hc', Hd); 3.71 (s, 
$1 \mathrm{H}, \mathrm{Ha}) ; 4.39$ (q, $\left.2 \mathrm{H}, J=7 \mathrm{~Hz}, \mathrm{OCH}_{2} \mathrm{CH}_{3}\right) ; 6.20$ (s, 2H, H2); 7.08 (s, 1H, H4); 7.37 (s, 1H, H9); 8.75 (s, 1H, H8); 9.72 (d, 1H, H1'); 9.83 (s, 1H, H3'). ${ }^{13} \mathrm{C}-\mathrm{NMR}(50$ MHz, DMSO-d $\left.{ }_{6}, \delta, p p m\right): 14.7\left(\mathrm{COOCH}_{2} \underline{C H}_{3}\right) ; 24.7$ (Cc and $\left.\mathrm{Cc}^{\prime}\right) ; 25.9(\mathrm{Cd}) ; 33.1$ (Cb and $\left.\mathrm{Cb}^{\prime}\right) ; 48.6$ (Ca); $62.4\left(\mathrm{COOCH}_{2} \mathrm{CH}_{3}\right) ; 103.2$ (C2); 103.4 (C4); 104.9 (C9); 108.7 (C7); 119.7 (C10a); 141.9 (C8); 146.3 (C11a); 147.3 (NHCONH); 150.4 (C1a); 153.7 (C3a); 154.5 (C6); 166.7 ( $\left.\mathrm{COOCH}_{2} \mathrm{CH}_{3}\right)$ (Fig. 1B). Elemental analysis: for $\mathrm{C}_{20} \mathrm{H}_{23} \mathrm{~N}_{3} \mathrm{O}_{5}(385.4 \mathrm{~g} / \mathrm{mol})$ : calcd. (\%): C, 62.33; H, 6.01; N, 10.90; found (\%): C, 62.79; H, 6.33; N, 9.74.

\section{Drug treatment}

Animals were pre-treated with carboxymethylcellulose (vehicle), celecoxib (cyclooxygenase-2 inhibitor; $100 \mathrm{mg}$ / $\mathrm{kg}$ ) or thalidomide (TNF- $\alpha$ inhibitor; $100 \mathrm{mg} / \mathrm{kg}$ ) as positive controls or L-998 $(10,100,200 \mathrm{mg} / \mathrm{kg})$ by gavage, $4 \mathrm{~h}$ LPS inhalation. For in vitro experiments with LPS-stimulated peritoneal macrophages, $0.5 \%$ DMSO (vehicle) or L-998 (1, 10, 100 and 1,000 $\mu \mathrm{M})$ was incubated with LPS concurrently. No L-998induced gross behavioral or functional signs of acute toxicity were detected in mice at the highest dose used (200 mg/kg). Also, MTT tests showed no evidence of cytotoxicity at a dose of $1,000 \mu \mathrm{M}$ during the time course of the present experiments (data not shown).

\section{LPS inhalation}

Experiments were performed as described previously [17]. Briefly, animals were randomly divided into 3 groups. In the first group, the animals inhaled $2 \mathrm{ml}$ aerosolized saline ( $\mathrm{NaCl} 0.9 \%$ ) for $10 \mathrm{~min}$; in the second group, the mice inhaled Escherichia coli LPS (lot 55:B5 from Difco Lab., USA) dissolved in $2 \mathrm{ml}$ saline at a concentration of $0.5 \mathrm{mg} / \mathrm{ml}$ for the same amount of time. In the last group, the animals were treated with L-998, via gavage, $4 \mathrm{~h}$ before the LPS inhalation under the same conditions. The inhalation chamber was made with a 11 Büchner funnel adapted with conical glass tubes coupled to a manometer. Mice were put inside the tubes to inhale saline or LPS.

\section{TNF instillation}

In certain experiments, we utilized the lung inflammation model induced by an intranasal instillation of recombinant TNF- $\alpha$. Animals were mildly anesthe- tized with ether and were instilled with $50 \mu 1 \mathrm{TNF}-\alpha$ $(0.5 \mu \mathrm{g} / \mathrm{mice})$ after reflex depression. In control animals, saline was instilled.

\section{Bronchoalveolar lavage fluid (BALF)}

Tracheas were cannulated, and BALF was obtained by intratracheal instillation of $1.5 \mathrm{ml}$ saline $(\mathrm{pH} \mathrm{7.4)}$ into the exposed lungs maintained within the thoracic cavity [9]. The lavage fluid was infused 3 times into the lungs before final collection. The fluid was withdrawn and stored on ice. Total cell number was determined with a Z1 Coulter Counter (Beckman Coulter, USA). Differential cell counts were performed on cytospin preparations (Shandon Cytospin, Thermo Fisher Scientific, USA) stained with Diff-Quik (Baxter Dade, Switzerland). At least 200 cells/BALF sample were counted using standard morphological criteria. Results are expressed as the numbers of cell populations per milliliter. The remaining BALF was centrifuged $(400 \times \mathrm{g}$ for $10 \mathrm{~min}$ ), and the supernatant was collected and stored at $-20^{\circ} \mathrm{C}$ for IL- $1 \beta$, TNF- $\alpha, \mathrm{KC}$ and MCP-1 assays. For western blotting and $\mathrm{NF}-\kappa \mathrm{B}$ assays, lung tissues were separated, and cytoplasmic and nuclear extracts were prepared immediately.

\section{Cytokines and chemokines}

The levels of the proinflammatory cytokines TNF- $\alpha$ and IL- $1 \beta$ and the chemokines KC and MCP-1 were determined in BALF using commercially available ELISA kits with rat anti-mouse monoclonal and polyclonal antibodies (detection limits of $10 \mathrm{pg} / \mathrm{ml}$ ) according to the manufacturer's recommended protocol (R\&D Systems, UK). Mouse recombinant cytokine standards were used in every assay. For the measurements of proinflammatory cytokines and chemokines in mice challenged with LPS, undiluted BALF was assayed in all animals.

\section{Preparation of tissue extracts}

Whole lung nuclear extracts were performed as previously described [9]. After BALF withdrawal, perfused lungs were excised, homogenized and incubated for $15 \mathrm{~min}$ in $500 \mu \mathrm{l}$ buffer A [10 mM HEPES ( $\mathrm{pH}$ 7.9), $10 \mathrm{mM} \mathrm{KCl}, 0.1 \mathrm{mM}$ EDTA, $0.1 \mathrm{mM}$ EGTA, $1 \mathrm{mM}$ DTT, $0.25 \% \mathrm{NP}-40 \mathrm{v} / \mathrm{v}, 0.5 \mathrm{mM}$ PMSF, $100 \mu \mathrm{M}$ orthovanadate, and $1 \mathrm{mM} \mathrm{NaF}]$ at $4{ }^{\circ} \mathrm{C}$. After centrifugation $(15,000 \times \mathrm{g}$ for $30 \mathrm{~s})$, supernatants were col- 
lected and stored at $-70^{\circ} \mathrm{C}$ for $\mathrm{p} 38$ MAPK detection. Pellets were resuspended and incubated in buffer $\mathrm{C}$ [20 mM HEPES (pH 7.9), $0.4 \mathrm{M} \mathrm{NaCl}, 0.1$ mM EDTA, $0.1 \mathrm{mM}$ EGTA, $10 \%$ glycerol $\mathrm{v} / \mathrm{v}, 1 \mathrm{mM}$ DTT, and $1 \mathrm{mM}$ PMSF] at $4^{\circ} \mathrm{C}$ for $15 \mathrm{~min}$. Extracts were centrifuged, and supernatants were frozen at $-70^{\circ} \mathrm{C}$. Cytoplasmic and nuclear protein levels were measured by the Bradford method (Bio-Rad Laboratories, USA).

\section{Isolation and treatment of peritoneal macrophages}

Cells from normal C57BL/6 mice were collected by lavage of the peritoneal cavity with $5 \mathrm{ml}$ RPMI 1640/sodium bicarbonate medium, then washed 3 times with the same medium and counted in a Neubauer chamber. In order to isolate macrophages, $10^{6}$ cells were resuspended in 24-well plates and allowed to attach for $1 \mathrm{~h}$ at $37^{\circ} \mathrm{C}$. Subsequently, the medium was replaced to remove nonadherent cells. Adherent macrophages were stimulated with $1 \mu \mathrm{g} / \mathrm{ml}$ LPS for $1 \mathrm{~h}$ in the presence of different concentrations of L-998, SB202190 $(10 \mu \mathrm{M})$ or vehicle, followed by the addition of $100 \mu \mathrm{l}$ sample buffer ( $20 \%$ glycerol, $10 \%$ SDS, $20 \% \beta$-mercaptoethanol, 1 mM Tris, $\mathrm{pH}$ 6.8) per well, boiling for $5 \mathrm{~min}$ and centrifugation for $10 \mathrm{~min}$ at $6,000 \times \mathrm{g}$. The supernatants were saved and stored at $-20{ }^{\circ} \mathrm{C}$ for western blot assays.

\section{Immunoblot assays}

Whole cell lysates were separated by $10 \%$ SDSPAGE and then electro-transferred to nitrocellulose membranes [9]. Membranes were pre-incubated for $1 \mathrm{~h}$ at room temperature in Tris-buffered saline, $\mathrm{pH}$ 7.6, containing $0.05 \%$ Tween- 20 and $3 \%$ BSA. Nitrocellulose membranes were incubated with phosphorylated p38- or total p38-specific antibodies. Immunoreactive bands were then detected by incubation with anti-rabbit IgG conjugated to horseradish peroxidase and enhanced chemiluminescence reagents (Amersham Biosciences, USA).

\section{Statistical analyses}

Data are presented as the means \pm SEM. Comparisons were made by analysis of variance (ANOVA). Posthoc tests, Dunnett's T3 and Tukey's, were also used to identify differences between values. A value of $p<$ 0.05 was considered statistically significant. In vitro inhibitory effect of L-998 on p38 MAPK phosphorylation evaluated by immunoblot experiments was graphically represented using a log concentrationeffect plot, and the curve fit and $\mathrm{IC}_{50}$ calculations were performed by nonlinear regression analysis (Prism 4.0, GraphPad Software, USA).

\section{Results}

\section{L-998 inhibits LPS-induced neutrophil accumulation in BALF}

Acute lung inflammation induced by aerosolized bacterial LPS is characterized by the production of inflammatory mediators and neutrophil recruitment in the BALF and can be used as a bioassay to evaluate anti-inflammatory drug candidates [17]. In our experiments, we found that inhalation of LPS elicited a massive recruitment of neutrophils when compared to saline inhalation, and this effect was significantly inhibited by the control anti-inflammatory drugs thalidomide (TNF- $\alpha$ inhibitor) or celecoxib (COX-2 selective inhibitor) (Fig. 2B). These results are similar to what we $[30,33]$ and others $[3,4]$ have previously described. In the case of L-998, preliminary experiments using different doses $2 \mathrm{~h}$ before LPS challenge did not result in decreased inflammation (Fig. 2A, maximal dose of $200 \mathrm{mg} / \mathrm{kg}$ is shown). However, when administered $4 \mathrm{~h}$ prior to LPS treatment, an inhibitory effect on neutrophil lung accumulation was evident with the higher doses, and the effect was equivalent to that of thalidomide and celecoxib treatment (Fig. 2B).

\section{L-998 inhibits LPS-induced cytokine but not chemokine release in BALF}

Because oral administration of L-998 reduced neutrophil migration to the lungs, we investigated whether the levels of important inflammatory mediators were altered. In agreement with previous reports $[17,20$, $25]$, the concentrations of the proinflammatory cytokines TNF- $\alpha$ (Fig. 3A) and IL-1 $\beta$ (Fig. 3B) and the chemokines KC (Fig. 3C) and MCP-1 (Fig. 3D) in the BALF of mice that were exposed to aerosolized LPS increased drastically (from 3- to 15-fold, depending on the mediator). Interestingly, pretreatment with L-998 significantly prevented the upsurge of TNF- $\alpha$ and IL-1 $\beta$ but not that of the chemokine levels (Fig. 3). 

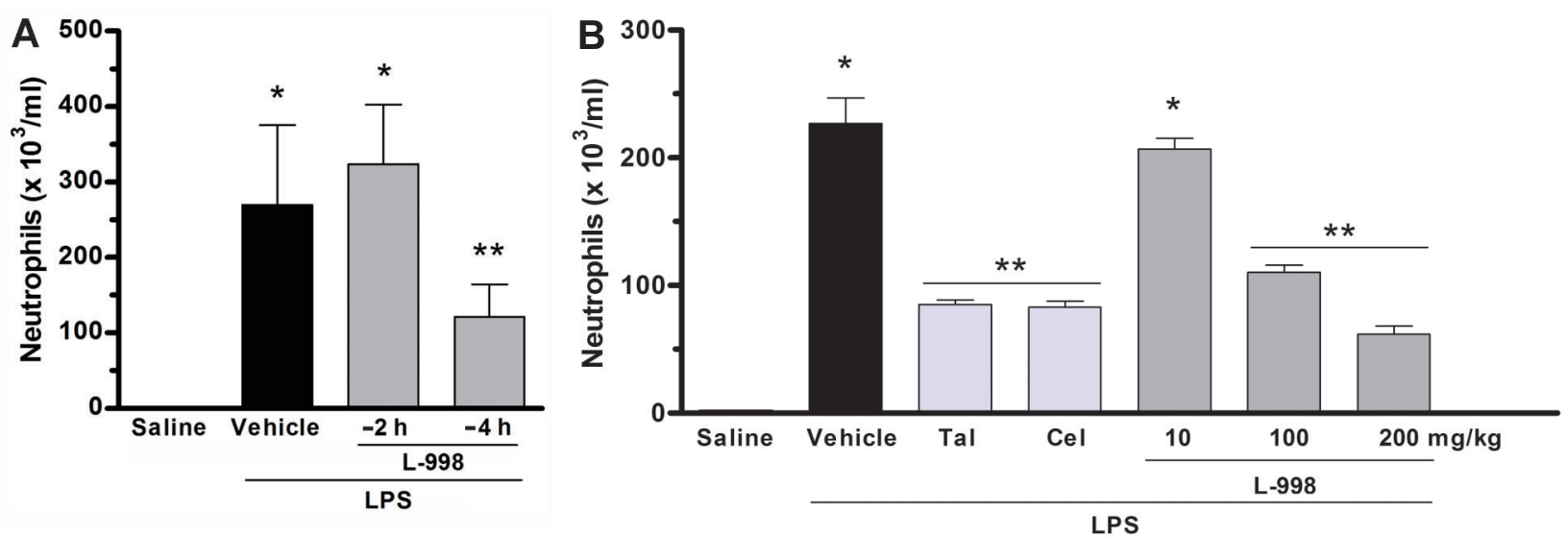

Fig. 2. L-998 inhibits LPS-induced neutrophilia in bronchoalveolar lavage fluid (BALF). Before the inhalation of aerosolized LPS (0.5 mg/ml), BALB/c mice were pretreated (A) with vehicle or L-998 $(200 \mathrm{mg} / \mathrm{kg})$ by gavage for 2 or $4 \mathrm{~h}$ or $(\mathbf{B})$ with vehicle, thalidomide (Tal, $100 \mathrm{mg} / \mathrm{ml})$, celecoxib (Cel, $100 \mathrm{mg} / \mathrm{ml}$ ) or L-998 (10, 100 and $200 \mathrm{mg} / \mathrm{kg}$ ) by gavage for $4 \mathrm{~h}$. BALF was analyzed $3 \mathrm{~h}$ later. Control animals inhaled a saline aerosol. The results are expressed as the means \pm SE $(n=6)$. ${ }^{*} p<0.05$ compared to saline; ${ }^{* *} p<0.01$ compared to vehicle
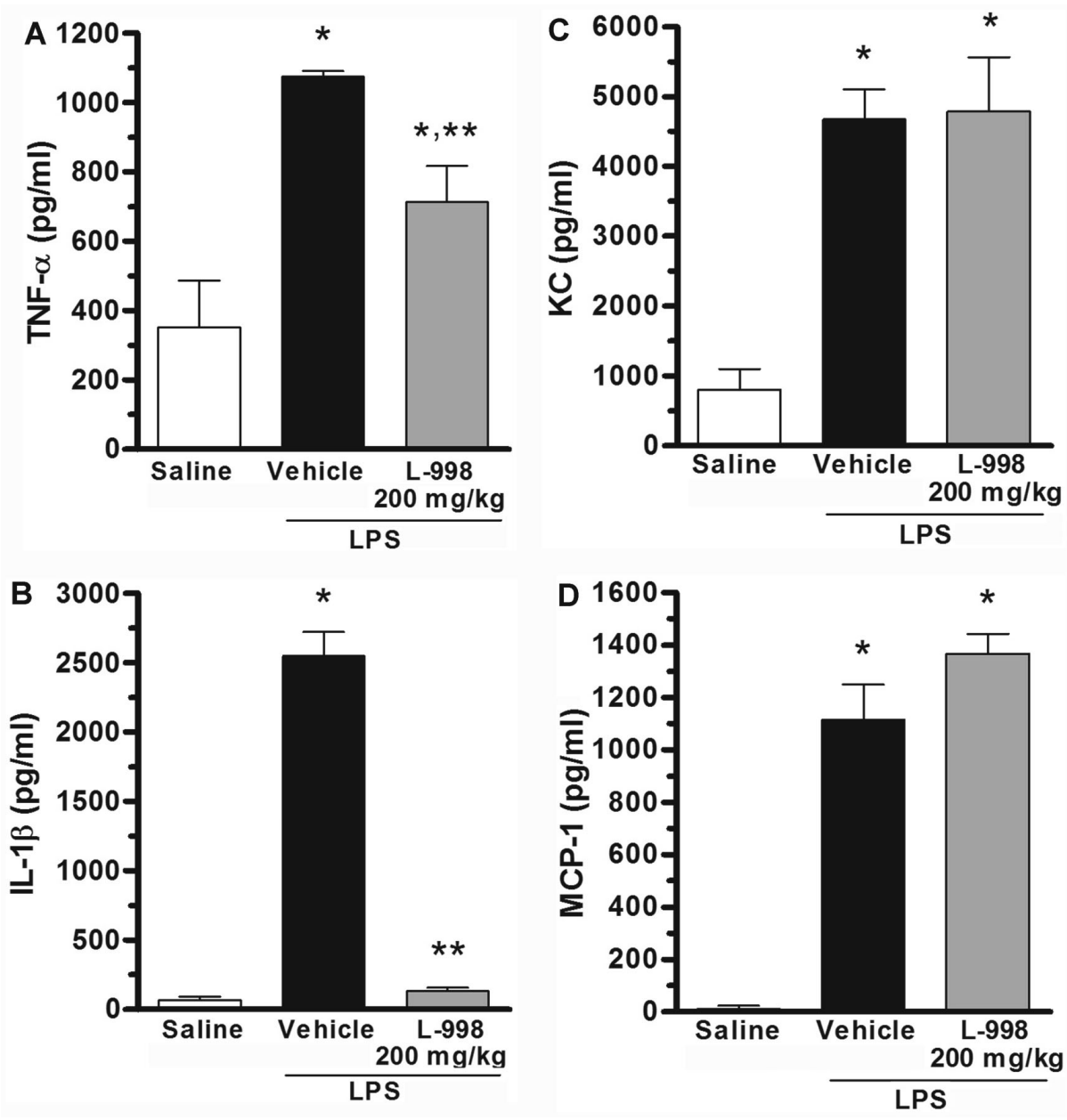

Fig. 3. Cytokine and chemokine levels in the BALF of mice treated with L-998. BALB/C mice were pretreated with vehicle or L-998 (200 mg/kg) by gavage $4 \mathrm{~h}$ before inhalation of aerosolized LPS $(0.5 \mathrm{mg} / \mathrm{ml})$. The concentrations of (A) TNF- $\alpha,(\mathbf{B}) \mathrm{IL}-1 \beta,(\mathbf{C}) \mathrm{KC}$ and (D) MCP- 1 were measured in the BALF $3 \mathrm{~h}$ later by ELISA. Control animals inhaled a saline aerosol. The results are expressed as the means \pm SE $(n=6)$. ${ }^{*} p<0.05$ compared to saline; ${ }^{* *} \mathrm{p}<0.01$ compared to vehicle 


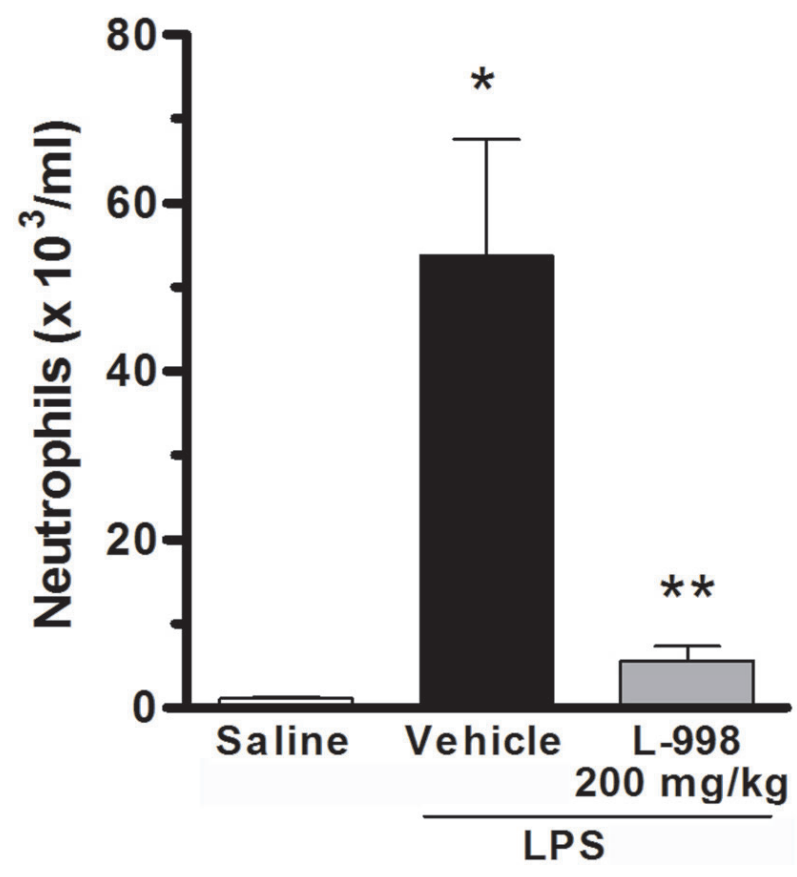

Fig. 4. L-998 inhibits TNF- $\alpha$-induced neutrophilia in BALF. BALB/C mice were pretreated with vehicle or L-998 $(200 \mathrm{mg} / \mathrm{kg})$ by gavage $4 \mathrm{~h}$ before intranasal TNF- $\alpha$ instillation $(0.5 \mu \mathrm{g} / \mathrm{mice})$, and BALF was analyzed $3 \mathrm{~h}$ later. Control animals received intranasal saline instillation. The results are expressed as the means \pm SE $(n=5-11) .{ }^{*} p<$ 0.05 compared to saline; ${ }^{* *} p<0.01$ compared to vehicle

\section{L-998 inhibits TNF- $\alpha$-induced neutrophil accumulation in BALF}

To verify whether the effect of L-998 on neutrophil recruitment involves a signaling component upstream or downstream of TNF- $\alpha$ release by alveolar macrophages, acute lung inflammation was induced by intranasal instillation of recombinant TNF- $\alpha$. Figure 4 shows that the L-998 treatment significantly decreased neutrophil accumulation $(92 \%)$ in the BALF of TNF- $\alpha$-treated mice, indicating that pathways downstream of cytokine secretion are also affected by L-998.

\section{L-998 inhibits LPS-induced p38 MAPK phosphorylation in lung tissue and in isolated macrophages}

Studies with monocytes and alveolar macrophages have shown that the p38 MAPK signaling is critical for LPS-induced cytokine release. Because L-998 was
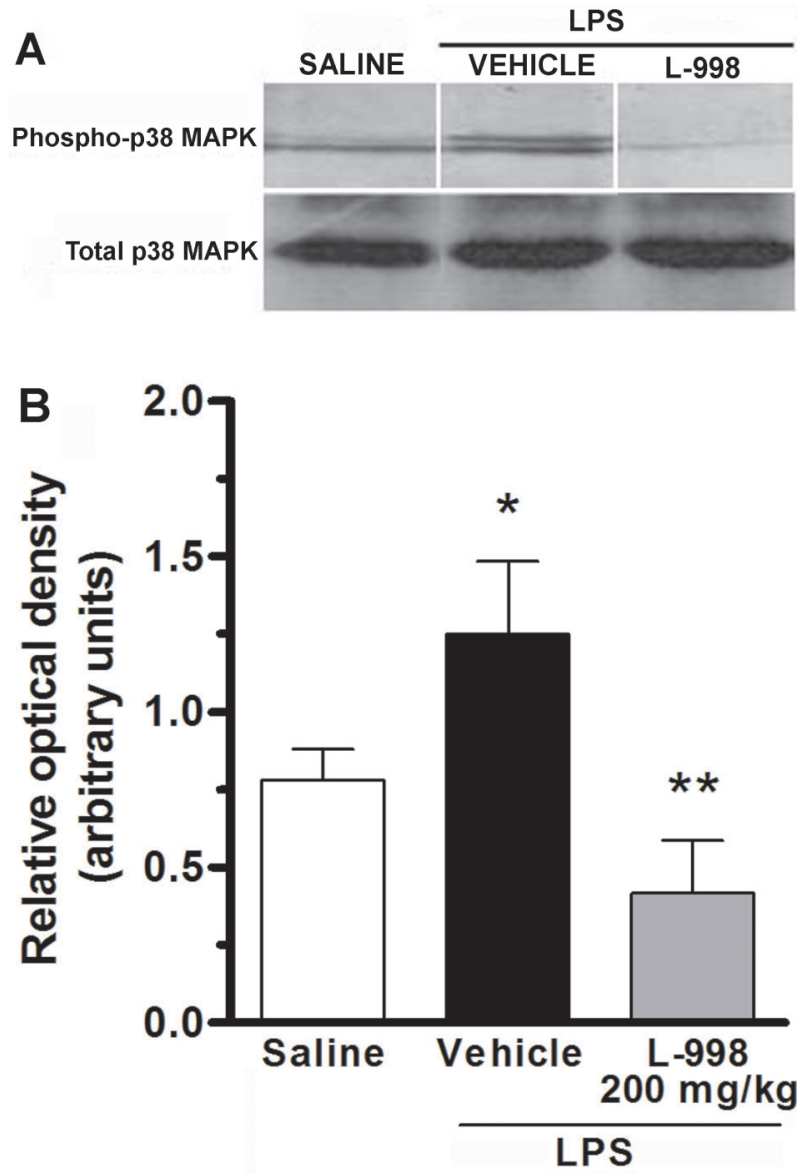

Fig. 5. L-998 prevents LPS-induced p38 MAPK phosphorylation in lung tissue. (A) Representative blot of phosphorylated and total p38 MAPK expression in the lung tissue of mice pretreated with vehicle or L-998 (200 mg/kg) by gavage $3 \mathrm{~h}$ after aerosolized LPS inhalation. Control animals inhaled a saline aerosol. (B) Relative values of phosphorylated p38 MAPK normalized to total p38 MAPK levels are indicated. The results are expressed as the means \pm SE $(n=3)$. * $p<$ 0.05 compared to saline; ${ }^{* *} p<0.01$ compared to vehicle

synthesized as a p38 MAPK inhibitor and effectively inhibited cellular migration and cytokine production, we examined whether this compound could affect p38 phosphorylation in lung tissue lysates of mice that had inhaled LPS. As illustrated in Figure 5, the phosphorylated (active) form of this MAPK was increased by LPS stimulation, and this phosphorylation was significantly prevented by L-998 treatment. In fact, there was even a slight decrease in p38 MAPK activation when compared to the saline inhalation group. No significant changes were observed with regard to the levels of total p38 MAPK (Fig. 5).

To further assess the pharmacological action of L-998 as a p38 MAPK inhibitor, we evaluated the ability of the drug to affect LPS-induced p38 MAPK 

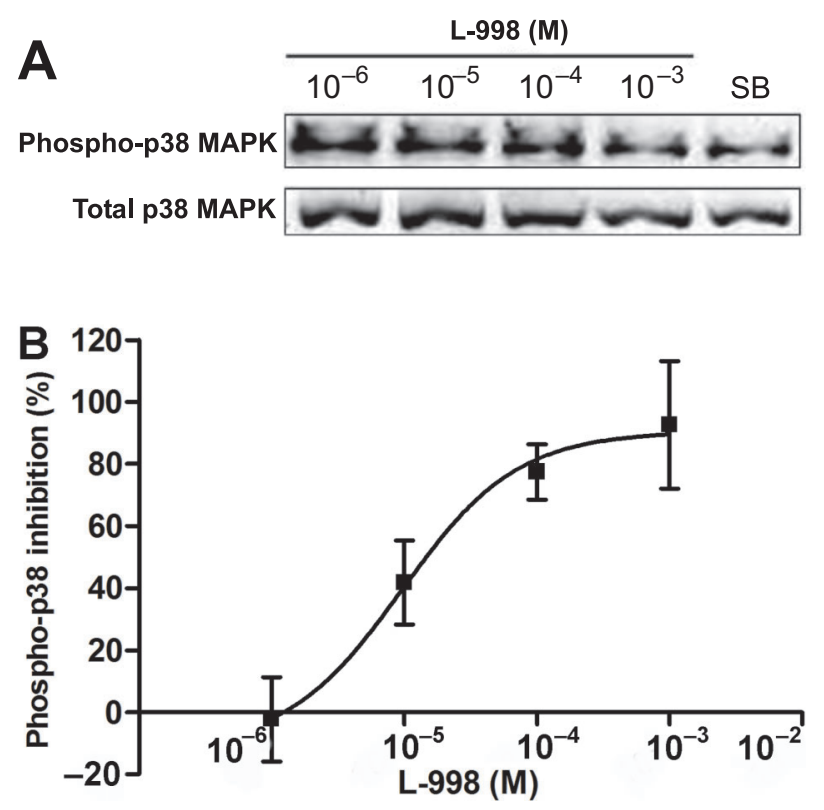

Fig. 6. L-998 prevents LPS-induced p38 phosphorylation in peritoneal macrophages in a concentration-dependent manner. (A) Representative blot of phosphorylated and total p38 MAPK expression in peritoneal macrophages incubated with LPS and L-998 (1-1000 $\mathrm{MM})$ or SB202190 (10 $\mu \mathrm{M})$. (B) Relative values of phosphorylated p38 MAPK normalized to total p38 MAPK levels, where 100\% inhibition was evaluated by incubation with LPS + SB202190 (100 $\mu \mathrm{M})$ and 0\% by LPS alone. The fitted curve was obtained by nonlinear regression using the model of one independent saturable process. Each point corresponds to the mean \pm SE $(n=3)$

activation in primary cultured peritoneal macrophages in vitro. Figure 6 shows that L-998 can indeed inhibit macrophage p38 MAPK stimulation, with an experimental $\mathrm{IC}_{50}$ around $14 \pm 9 \mu \mathrm{M}$. Therefore, these results demonstrate that L-998 antagonizes the activation of p38 MAPK by LPS in vitro and in vivo.

\section{Discussion}

The main findings of this study were that the orally bioavailable compound L-998 exerted robust antiinflammatory effects in the lungs of mice exposed to LPS. These effects were most likely mediated by the inhibition of p38 MAPK activation.

Lung diseases, such as focal pneumonias, cystic fibrosis and ARDS, present important inflammatory components [23], with local or systemic endotoxin release. Experimentally, LPS inhalation induces lung inflammation, with a marked increase in neutrophil recruitment in the airway tissue and lumen. This acute inflammatory model is characterized by a timedependent release of TNF- $\alpha$, and its synthesis precedes the influx of neutrophils. In addition to TNF- $\alpha$, LPS inhalation also induces IL-1 $\beta$ release [36]. Antiinflammatory drugs, as TNF- $\alpha$ antagonists and corticosteroids, inhibit those inflammatory mediators but present numerous adverse effects and have failed to produce more sustained benefits in vivo $[15,38]$. Thus, it is important to design drugs that act on other cellular targets. p38 MAPK has emerged as a central kinase involved in signal transduction pathways that lead to cytokine synthesis and inflammation induced by different experimental conditions, e.g., LPS or cigarette smoke $[9,27,31]$. Various p38 MAPK inhibitors, such as M39, SB239063 and SB203580, have been shown to attenuate the production of inflammatory mediators, including TNF- $\alpha$, MIP-2 and IL-6. They also have been demonstrated to attenuate neutrophil recruitment into the lungs in animal models of pulmonary inflammation [24, 31, 36]. Moreover, the ability of p38 MAPK inhibitors to block TNF- $\alpha$ synthesis has been explored in the treatment of other inflammatory diseases, and they have been shown to impede the development of rheumatoid arthritis in small-animal models [34].

Certain currently available p38 MAPK inhibitors are in phase I or phase II clinical trials, but many others have been withdrawn due to intolerable side effects and toxicity, which appear to be the result of cross-reactivity with different off-target proteins, including other kinases $[10,13,28]$. These facts motivate the research and design of novel, orally active p38 MAPK inhibitors.

In the present work, L-998 inhibited the release of the cytokines TNF- $\alpha$ and IL- $1 \beta$ and did not interfere with the chemokines KC and MCP-1. The recruited neutrophils contribute to the local production of TNF- $\alpha$ and KC [16]. Animals treated with L-998, despite their lack of change in $\mathrm{KC}$ levels, have decreased alveolar neutrophil accumulation. In vivo leukocyte migration is a complex event involving two complementary steps: a) leukocyte locomotion induced by chemoattractant factors, including chemokines, and b) adhesion molecule expression on endothelial cells induced by inflammatory mediators, including TNF- $\alpha$. TNF- $\alpha$ is unable to promote chemotaxis in vitro, although it is crucial for enhanced expression of ICAM-1 [45]. These findings are in apparent contradiction with the previous demonstration that ip ad- 
ministration of TNF- $\alpha$ induces neutrophil recruitment [7]. A possible explanation for this contradiction is that exogenous TNF- $\alpha$ induces adhesion molecule expression and the release of other mediators that are able to induce neutrophil locomotion. Here, as described by Canetti et al. [7], when TNF- $\alpha$ was instilled, neutrophil migration was evident in BALF, and L-998 also evoked a more striking inhibition of this process, probably because the release of mediators induced by TNF- $\alpha$ was inhibited by L-998. Thus, the inhibition of p38 signaling impairs the release of TNF- $\alpha$ and secondary mediators, leading to lower alveolar neutrophil accumulation. A similar effect was reported by Nick et al. [36, 37], who demonstrated that the recovery of TNF- $\alpha$ in the airspaces was reduced by a $\mathrm{p} 38$ MAPK inhibitor, M39, while MCP-1 and KC levels were not affected. This p38 MAPK inhibitor also reduced $\mathrm{KC}$-induced neutrophil lung influx, and loss of neutrophil chemoattractant action of $\mathrm{KC}$ and MIP-2 was achieved in vitro. Indeed, neutrophil activation by itself appears to be also selectively impaired by p38 MAPK inhibition [37].

It is important to mention that these authors suggested that the relative lack of p38 MAPK-dependent $\mathrm{KC}$ and MCP-1 release would have a protective effect because these chemokines contribute to the recruitment of leukocytes that are involved in inflammation resolution [38]. For instance, MCP-1 appears to be involved in wound repair, and inhibition of MCP-1 may also retard tissue healing and regeneration $[12,32$, 40]. Conversely, it has been reported that MCP-1 plays no important role in ALI [6].

The time-dependent effects of L-998 on neutrophil migration may be a consequence of drug pharmacokinetics. L-998 was administered by the enteral route; therefore, it is conceivable that some delay may occur when compared to other common experimental routes of administration (e.g., intravenous, intraperitoneal). Because L-998 distribution and biotransformation is still unknown, it is important to note that a product of L-998 metabolism might be the more pharmacologically active substance.

Using the synthetic strategy of bioisosterism, L-998 was designed to inhibit p38 MAPK [31]. The results obtained in lung tissue as well as with isolated macrophages confirmed this mechanism of action. Additionally, our preliminary experiments that evaluated the activation of lung NF- $\mathrm{kB}$, a p38 MAPK-activated factor critical for the expression of cytokines involved in the pathogenesis of inflammatory diseases [1, 21,
$24,31]$, suggest that it is partially impaired by L-998 treatment (data not shown). Treatment of LPS-challenged peritoneal macrophages with L-998 in vitro resulted in an approximate $\mathrm{IC}_{50}$ of $15 \mu \mathrm{M}$. Although L-998 potency appears to be somewhat low compared to other well-known p38 MAPK inhibitors, usually the potency is estimated in protocols that measure p38 kinase activity. Interestingly enough, however, when several studies have utilized immunoblot techniques to detect phosphorylated p38 MAPK, they have shown similar $\mathrm{IC}_{50}$ ranges $(1-50 \mu \mathrm{M})$ for various distinct selective p38 MAPK inhibitors (SB203580 [36], SB239063 and SD-282 [41], SB202190 [46]), at least in macrophages.

Importantly, considering the anti-inflammatory effects of L-998 in acute lung inflammation models and the key role of p38 MAPK activation in inflammation and pain [22], experiments performed in a novel model of experimental rheumatoid arthritis, in which the dorsal flexion of inflamed tibiotarsal articulation elicits an inflammatory process with hypernociception [19], indicated that L-998-treated mice present significantly higher mechanical thresholds than the ones that received vehicle alone (data not shown). The fact that L-998 produced significant analgesia raises its potential as a novel drug.

\section{Conclusion}

LASSBio-998 is characterized by an anti-inflammatory profile, and treatment with L-998 suppresses LPSinduced lung inflammation. This is supported by a reduction in neutrophil infiltration, down-regulation of inflammatory cytokines (i.e., TNF- $\alpha$ and IL-1 $\beta$ ) and inhibition of $\mathrm{p} 38$ MAPK phosphorylation in vitro and in vivo. Therefore, our study revealed that LASSBio-998 could become a clinically relevant anti-inflammatory drug candidate.

\section{Acknowledgments:}

This work was supported by grants from the Conselho Nacional de Pesquisa (CNPq, 420015/05-1, 310149/2006-1 and

151681/2008-2), IM-INOFAR (CNPq, 420.015/05-1), PRONEX,

FAPERJ and CAPES. We thank the excellent technical assistance of Sérgio R. Rosa and Prof. Waldiceu A. Verri, Jr. 


\section{References:}

1. Abraham E: Nuclear factor- $\kappa B$ and its role in sepsisassociated organ failure. J Infect Dis, 2003, 187, S364-S369.

2. Adcock IM, Chung KF, Caramori G, Ito K: Kinase inhibitors and airway inflammation. Eur J Pharmacol, 2006, 533, 118-132.

3. Aimbire F, Penna SC, Rodrigues M, Rodrigues KC, Lopes-Martins RA, Sertié JÁ: Effect of hydroalcoholic extract of Zingiber officinalis rhizomes on LPS-induced rat airway hyperreactivity and lung inflammation. Prostaglandins Leukot Essent Fatty Acids, 2007, 77, 129-138.

4. Aimbire F, Albertine R, de Magalhăes RG, LopesMartins RA, Castro-Faria-Neto HC, Zângaro RA, Chavantes MC, Pacheco MT: Effect of LLLT Ga-Al-As $(685 \mathrm{~nm})$ on LPS-induced inflammation of the airway and lung in the rat. Lasers Med Sci, 2005, 20, 11-20.

5. Bhatia M., Moochhala S: Role of inflammatory mediators in the pathophysiology of acute respiratory distress syndrome. J Pathol, 2004, 202, 145-156.

6. Bless NM, Huber-Lang M, Guo RF, Warner RL, Schmal H, Czermak BJ, Shanley TP et al.: Role of CC chemokines (macrophage inflammatory protein-1 $\beta$, monocyte chemoattractant protein-1, RANTES) in acute lung injury in rats. J Immunol, 2000, 164, 2650-2659.

7. Canetti C, Silva JS, Ferreira SH, Cunha FQ: Tumour necrosis factor- $\alpha$ and leukotriene $\mathrm{B}_{4}$ mediate the neutrophil migration in immune inflammation. Br J Pharmacol, 2001, 134, 1619-1628.

8. Castro P, Legora-Machado A, Cardilo-Reis L, Valença S, Porto LC, Walker C, Zuany-Amorim C, Koatz VLG: Inhibition of interleukin-1 $\beta$ reduces mouse lung inflammation induced by exposure to cigarette smoke. Eur J Pharmacol, 2004, 498, 279-286.

9. Castro P, Nasser H, Abrahăo A, Dos Reis LC, Rica I, Valença SS, Rezende DC et al.: Aspirin and indomethacin reduce lung inflammation of mice exposed to cigarette smoke. Biochem Pharmacol, 2009, 77, 1029-1039.

10. Chopra P, Kanoje V, Semwal A, Ray A: Therapeutic potential of inhaled p38 mitogen-activated protein kinase inhibitors for inflammatory pulmonary diseases. Expert Opin Investig Drugs, 2008, 17, 1411-1425.

11. Cloutier A, Ear T, Blais-Charron E, Dubois CM, Mc Donald PP: Differential involvement of NF- $\kappa B$ and MAP kinase pathways in the generation of inflammatory cytokines by human neutrophils. J Leuk Biol, 2007, 81, 567-577.

12. DiPietro LA, Reintjes MG, Low QE, Levi B, Gamelli RL: Modulation of macrophage recruitment into wounds by monocyte chemoattractant protein-1. Wound Repair Regen, 2001, 9, 28-33.

13. Dominguez C, Powers DA, Tamayo N: p38 MAP kinase inhibitors: many are made, but few are chosen. Curr Opin Drug Discov Devel, 2005, 8, 421-430.

14. Dumas J, Hatoum-Mokdad H, Sibley R, Riedl B, Scott WJ, Monahan MK, Lowinger TB et al.: 1-Phenyl-5pyrazolyl ureas: potent and selective p38 kinase inhibitors. Bioorg Med Chem Lett, 2000, 10, 2051-2054.

15. Esper AM, Martin GS: Evolution of treatments for patients with acute lung injury. Expert Opin Investig Drugs, 2005, 14, 633-645.
16. Garcia-Ramallo E, Marques T, Prats N, Beleta J, Kunkel SL, Godessarti N: Resident cell chemokine expression serves as the major mechanism for leukocyte recruitment during local inflammation. J Immunol, 2002, 169, 6467-6473.

17. Gonçalves de Moraes VL, Vargaftig B, Lefort J, Meager A, Chignard M: Effect of cyclo-oxygenase inhibitors and modulators of cyclic AMP formation on lipopolysaccharide-induced neutrophil infiltration in mouse lung. $\mathrm{Br}$ J Pharmacol, 1996, 117, 1792-1796.

18. Gordon T, Balmes J, Fine J, Sheppard DD: Airway oedema and obstruction in guinea pigs exposed to inhaled endotoxin. Br J Ind Med, 1991, 48, 629-635.

19. Guerrero AT, Verri Jr WA, Cunha TM, Silva TA, Rocha FA, Ferreira SH, Cunha FQ, Parada CA: Hypernociception elicited by tibio-tarsal joint flexion in mice: a novel experimental arthritis model for pharmacological screening. Pharmacol Biochem Behav, 2006, 84, 244-251.

20. Jansson AH, Eriksson C, Wang X: Effects of budesonide and $\mathrm{N}$-acetylcysteine on acute lung hyperinflation, inflammation and injury in rats. Vasc Pharmacol, 2005, 43, 101-111.

21. Je J, Lee JY, Jung KJ, Sung B, Go EK, Yu BP, Chung HY: NF- $\kappa B$ activation mechanism of 4-hydroxyhexenal via NIK/IKK and p38 MAPK pathway. FEBS Lett, 2004, 566, 183-189.

22. Ji RR: Mitogen-activated protein kinases as potential targets for pain killers. Curr Opin Investig Drugs, 2004, 5, 71-75.

23. Keyhanmanesh R, Boskabady MH, Khamneh S, Doostar Y: Effect of thymoquinone on the lung pathology and cytokine levels of ovalbumin-sensitized guinea pigs. Pharmacol Rep, 2010, 62, 910-916.

24. Kim HJ, Lee HS, Chong YH, Kang JL: p38 Mitogenactivated protein kinase up-regulates LPS-induced NF- $\kappa$ B activation in the development of lung injury and RAW 264.7 macrophages. Toxicology, 2006, 225, 36-34.

25. Lagente V, Planquois, JM, Leclerc O, Schmidlin F, Bertrand CP: Oxidative stress is an important component of airway inflammation in mice exposed to cigarette smoke or lipopolysaccharide. Clin Exp Pharmacol Physiol, 2008, 35, 601-605.

26. Lee HS, Kim HJ, Moon CS, Chong YH, Kang JL: Inhibition of c-Jun $\mathrm{NH}_{2}$-terminal kinase or extracellular signal-regulated kinase improves lung injury. Respir Res, 2004, 5, 23.

27. Lee JC, Young PR: Role of CSBP/p38/RK stress response kinase in LPS and cytokine signaling mechanisms. J Leuk Biol, 1996, 59, 152-157.

28. Lee MR, Dominguez C: MAP kinase p38 inhibitors: clinical results and an intimate look at their interactions with p38 $\alpha$ protein. Curr Med Chem, 2005, 12, 2979-2994.

29. Lima LM, Barreiro EJ: Bioisosterism: a useful strategy for molecular modification and drug design. Curr Med Chem, 2005, 12, 23-49.

30. Lima LM, Fraga CAM, Gonçalves-Koatz VL, Barreiro EJ: Thalidomide and analogs as anti-inflammatory and immunomodulator drug candidates. Anti-inflammatory Anti-allergy Agents Med Chem, 2006, 5, 79-95.

31. Liu S, Feng G, Wang G, Liu G: p38 MAPK inhibition attenuates LPS-induced acute lung injury involvement of NF-кB pathway. Eur J Pharmacol, 2008, 584, 159-165. 
32. Low QE, Drugea IA, Duffner LA, Quinn DG, Cook DN, Rollins BJ, Kovacs EJ, DiPietro, LA: Wound healing in MIP-1 $\alpha^{-. /-}$and MCP-1 $1^{-/-}$mice. Am J Pathol, 2001, 159, 457-463.

33. Machado AL, Lima LM, Araújo JX, Fraga CA, Koatz VL, Barreiro EJ: Design, synthesis and antiinflammatory activity of novel phthalimide derivatives, structurally related to thalidomide. Bioorg Med Chem Lett, 2005, 15, $1169-1172$.

34. Mihara K, Almansa C, Smeets RL, Loomans EE, Dulos J, Vink PM, Rooseboom M et al.: A potent and selective p38 inhibitor protects against bone damage in murine collageninduced arthritis: a comparison with neutralization of mouse TNF- $\alpha$. Br J Pharmacol, 2008, 154, 153-164.

35. Nagahira A, Nagahira K, Murafuji H, Abe K, Magota K, Matsui M, Oikawa S: Identification of a novel inhibitor of LPS-induced TNF- $\alpha$ production with antiproliferative activity in monocyte/macrophages. Biochem Biophys Res Commun, 2001, 281, 1030-1036.

36. Nick JA, Young SK, Arndt PG, Lieber JG, Suratt BT, Poch KR, Avdi NJ, et al.: Role of p38 mitogen-activated protein kinase in a murine model of pulmonary inflammation. J Immunol, 2000, 164, 2151-2159.

37. Nick JA, Young SK, Brown KK, Avdi NJ, Arndt PG, Suratt BT, Janes MS et al.: Selective suppression of neutrophil accumulation in ongoing pulmonary inflammation by systemic inhibition of $\mathrm{p} 38$ mitogen-activated protein kinase. J Immunol, 2002, 169, 5260-5269.

38. Raghavendran K, Pryhuber GS, Chess PR, Davidson BA, Knight PR, Notter RH: Pharmacotherapy of acute lung injury and acute respiratory distress syndrome. Curr Med Chem, 2008, 15, 1911-1924.

39. Redman AM, Johnson JS, Dally R, Swartz S, Wild H, Paulsen H, Caringal Y et al.: p38 Kinase inhibitors for the treatment of arthritis and osteoporosis: thienyl, furyl, and pyrrolyl ureas. Bioorg Med Chem, 2001, 11, 9-12.

40. Shireman PK, Contreras-Shannon V, Ochoa O, Karia BP, Michalek JE, McManus LM: MCP-1 deficiency causes altered inflammation with impaired skeletal muscle regeneration. J Leuk Biol, 2007, 81, 775-785.
41. Smith SJ, Fenwick PS, Nicholson AG, Kirschenbaum F, Finney-Hayward TK, Higgins LS, Giembycz MA et al.: Inhibitory effect of p38 mitogen-activated protein kinase inhibitors on cytokine release from human macrophages. Br J Pharmacol, 2006, 149, 393-404.

42. Sperandio da Silva GM, Sant'Anna CM, Barreiro EJ: A novel 3D-QSAR comparative molecular field analysis (CoMFA) model of imidazole and quinazolinone functionalized p38 MAP kinase inhibitors. Bioorg Med Chem, 2004, 12, 3159-3166.

43. Sugiyama K-I, Muroi M, Tanamoto K-I: A novel TLR4binding peptide that inhibits LPS induced activation of NF- $\mathrm{BB}$ and in vivo toxicity. Eur J Pharmacol, 2008, 594, $152-156$.

44. Ulich TR, Yi ES, Smith C, Remick D: Intratracheal administration of endotoxin and cytokines VII. The soluble interleukin-1 receptor and the soluble tumor necrosis factor receptor II (p80) inhibit acute inflammation. Clin Immunol Immunopathol, 1994, 72, 137-140.

45. Vieira SM, Lemos HP, Grespan R, Napimoga MH, DalSecco D, Freitas A, Cunha TM et al.: A crucial role for TNF- $\alpha$ in mediating neutrophil influx induced by endogenously generated or exogenous chemokines, KC/CXCL1 and LIX/CXCL5. Br J Pharmacol, 2009, 158, 779-789.

46. Zhou HY, Shin EM, Guo LY, Youn UJ, Bae K, Kang SS, Zou LB, Kim YS: Anti-inflammatory activity of 4-methoxyhonokiol is a function of the inhibition of iNOS and COX-2 expression in RAW 264.7 macrophages via $\mathrm{NF}-\kappa \mathrm{B}, \mathrm{JNK}$ and p38 MAPK inactivation. Eur J Pharmacol, 2008, 586, 340-349.

47. Zhou LH, Tu SJ, Shi DQ, Dai GY, Chen WX: Lowvalent titanium induced novel reductive cyclizations of $\alpha, \beta$-unsaturated nitrile compounds. Synthesis (Stuttgart), 1998, 6, 851-854.

Received: October 24, 2010; in the revised form: March 23, 2011; accepted: April 14, 2011. 